\title{
Improving pre-drilling efficiency by analysing geological prospecting data: a case study of a project in Nanshan, Shenzhen
}

\author{
Da Liu ${ }^{1}$, Zheng Liu², and Tianyu Chen ${ }^{3, *}$ \\ ${ }^{1}$ KWG Group Holdings, Shenzhen Company, Guangdong, China \\ ${ }^{2}$ Tianjin Chengjian University, Department of Civil Engineering, Tianjin, China \\ ${ }^{3}$ Shenzhen Boyuda Building Technology Ltd., Guangdong, China
}

\begin{abstract}
Pre-drilling is a widely used technique to get the detailed geological condition at the location of the bored pile foundation prior to its construction. It is often a necessary step for bored piles supported by strata, as its results are helpful for finalizing the pile length in design stage, which often requires the pile to be embedded into the rock strata at certain depth. The aim of the paper is to find the optimal (normally the lowest) point of rock strata at the purposed pile location, so that the optimal length required for the pile can be determined. To achieve this, geological prospecting data of the site needs to be analysed and the optimal pre-drilling point needs to be determined. The model developed by this study is based on the geological prospecting data and the pre-drilling results of a real project with a sharp slope of strata. It is found that by using the method introduced in this study, higher accuracy results could be obtained with less pre-drilling works required, hence the time and the cost of pre-drilling can be greatly reduced.
\end{abstract}

\section{Introduction}

Pile foundation is a common technology used by foundation of high-rise buildings and large size infrastructures due to its load bearing ability and stable performance. Many studies related to the quality control of large diameter bored piles during construction have been carried out in recent decades. Some in-situ advises and control skills are summarised to improve the quality of bored pile construction, e.g. [1-2].

Pre-drilling is a low-cost method to detect the actual geological condition for a pile foundation. As a kind of construction investigation, pre-drilling identifies the extraction samples from the exploration borehole to investigate the geological condition underground, detecting any weak interlayer, cavity or other adverse geological effects [3]. The purpose of pre-drilling is to report the location and depth of the specific strata layer(bearing layer) in which the pile foundation should be embedded as well as to find other buried objects in advance. The length of the pile foundation (the required length that the pile needs to be embedded into bearing layer plus the depth of rock strata) can hence be confirmed by referring to the design criteria and related standards[4-5].

Geological prospecting results can give a first view of the geological condition of the ground, hence it is beneficial in the design stage (i.e. choosing the foundation type), but so far it still has limited contribution in construction stage [6]. Traditionally, geological prospecting results are plotted as contour maps, which often has low resolution and is less reliable when compared to pre-drilling results. On the other hand, with complex underground geological conditions, more than one pre-drills are always suggested for one pile in order to correctly to distinguish the condition of bearing layer within the full cross-section [2]. Among them, the lowest strata level detected by those pre-drillings is always be treated as the desired depth of the strata.

Under the condition of karst geology which is quite common in Shenzhen, site operation will often encounter a variety of karst forms such as stone column, cavity and varying strata slope, in which case a single pre-drilling result may not be able to reflect the actual condition of the bearing layer underneath if not drilled deep enough [7].

Till today, no reliable method can identify the actual condition of rock within the cross-sectional area in a pile, which brings a huge risk of uncertainty in both quality and quantity control during pile construction period. To fill this research gap and improve the efficiency of predrilling, this study enhances the visibility of geological prospecting outcomes by establishing a 3D model via MATLAB, which has much higher resolution and hence can give an estimation of expected pre-drilling's and identify the optimal pre-drilling location. Additionally, the method of secondary pre-drilling locations estimation while needed is also introduced, and its potential contribution in construction settlements is discussed. Moreover, this paper develops an algorithm of using geological prospecting data, so it can be employed universally and be popularized easily.

* Corresponding author: tianyu_chen@outlook.com 


\section{Method}

The project is located in the central area of Shenzhen, which covers an area of over $10,000 \mathrm{~m}^{2}$ (about $170 \mathrm{~m}$ long and $60 \mathrm{~m}$ wide). an 84-point geological prospecting survey have been made ( 22 points were made out of the west boundary of site), covering a total area of $180 \mathrm{~m} \mathrm{x}$ $85 \mathrm{~m}$. Two tower buildings were designed in this project, the north building has 44 bored piles and the south building has 31 , with diameter ranges from $1600 \mathrm{~mm}$ to $2000 \mathrm{~mm}$. All data showed in this paper are recorded and summarised from the real work.

The first part of this work shows the process of verifying the pre-drilling result of the north building by using the geological prospecting data. After that the determination of optimal (deepest) point within the pile bottom area was carried out for each bored pile of the south building.

All coordinate mentioned in this work should refer to the 1956 Yellow Sea Datum system.

\subsection{Pre-drilling Plan}

As traditional plan often instructs, the pre-drilling is made at the centre of the bored pile, with $10 \mathrm{~cm}$ of the diameter of its drilled sample. Practically, more than one pre-drilling are needed for those piles' diameter equal or more than $2 \mathrm{~m}$. In this case, 13 points of pre-drilling are added after collecting and preliminary analysing the first 44 data.

\subsection{Numerical Simulation}

Firstly, mesh the region of the geological prospecting survey [8] to $1000 \times 1000$ points by using the $x$ and $y$ coordinates corresponding to the depth result $(z)$ as shown in Figure 1. Then $z$ for each meshed grid was calculated. The difference between the meshed $\mathrm{x}$ coordinate $(x)$ and the $\mathrm{x}$-coordinate of one specific predrilling location $\left(x_{c}\right)$ can be written as: $d x=x_{c}-x$; similarly, it for $y$-coordinate can be written as: $d y=y_{c^{-}} y$. The minimum $d x$ and $d y$ can be shown as:

$$
\begin{aligned}
& d x_{\text {min }}=\left|\mathrm{x}_{\mathrm{c}}-\mathrm{x}_{\mathrm{m}}\right| \\
& d y_{\text {min }}=\left|\mathrm{y}_{\mathrm{c}}-\mathrm{y}_{\mathrm{n}}\right|
\end{aligned}
$$

in Equation 1 and 2, $m$ and $n$ should equal to the size of the mesh grid, which should be 1 to 1000 respectively in this study. Thus $z_{m n}$ can be found, and it is the closest point in the mesh grid to the specific pre-drilling location. Theoretically, the $d x$ and $d y$ could reach a maximum value of $9 \mathrm{~cm}$ and $4.25 \mathrm{~cm}$ respectively, however in this real case, the mean $d x$ and $d y$ value is obtained to be $4.3 \mathrm{~cm}$ and $2.2 \mathrm{~cm}$ respectively.

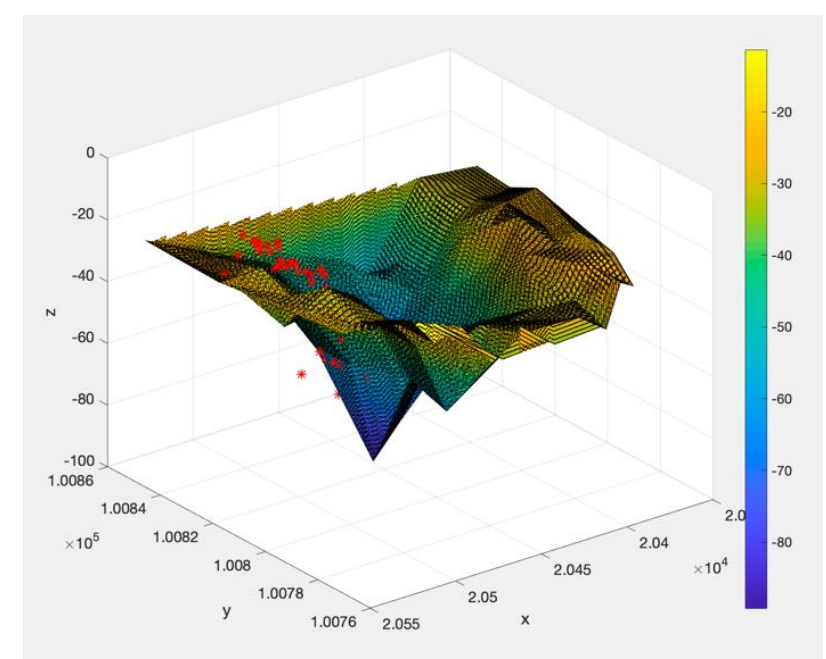

Fig. 1. 3-D view of the data map of the geological prospecting data. Red stars indicate the location and the depth of strata detected by pre-drilling.

With the aid of data map, the location of each bored pile could then be briefly shown by 12 outer surrounding points (30-degree apart from each other), together with the central point of the pile. Though the folded layers of rock strata, with extreme sharp angles, occurs in the nature, the boundary between soil and rock strata always has gentle slope [8], so these points can properly represent the pile shape in this case. The $\mathrm{x}$ and $\mathrm{y}$ coordinates $\left(x_{p}\right.$ and $\left.y_{p}\right)$ of these 13 points are then determined for each bored pile. Similar to Equation 1 and 2, Equation 3 and 4 are derived:

$$
\begin{aligned}
& d x_{p, \min }=\left|\mathrm{x}_{\mathrm{p}}-\mathrm{x}_{\mathrm{m}}\right| \\
& d y_{p, \text { min }}=\left|\mathrm{y}_{\mathrm{p}}-\mathrm{y}_{\mathrm{n}}\right|
\end{aligned}
$$

As result, a total number of $13 z_{p, I}$ value ( $i=1$ to 13 ) could be calculated by Equation 3 and 4 , and the smallest number among them $\left(z_{p, \min }\right)$ indicates the maximum depth value among those 13 points for the specific bored pile, and hence, the x-coordinate $\left(x_{\text {min }}\right)$ and the y-coordinate $\left(y_{\min }\right)$ of the deepest point could be found. If the maximum depth value is significantly higher than other points, it might indicates the existence of a strata slope, and the proposed pre-drilling point should be switched from the center point to the point which shows maximum depth.

On the other hand, if all 13 points shows similar depth value, this may indicate a very gentle slope of strata, hence the central point could still be used for drilling.

\section{Result and Discussion}

First part of this section is showing the way of verifying the pre-drilling result to the geological report, and a few cases of matching an un-matching are discussed. Then the optimal pre-drilling location is worked out, and its accuracy is discussed. 


\subsection{Verifying the Pre-drilling result}

Comparing to traditional contour plots, the 3-D map of geological prospecting data is much more accurate and useful due to its higher resolution of data points, this method can be applied to any size and shape of lands without boundary effects, because the survey area of geological prospecting data is normally larger than the site boundary.

In this study, the predrilling results of the north building is compared to the geological prospecting results (shown in Fig. 2). The geological report is plotted with the natural number along $\mathrm{X}$-axis, and the number is constantly named after an "S" shape for a building with a rectangular plan. It shows that pre-drilling data are systematically higher at those peaks, which means the weathered stone layer determined in pre-drilling is shallower. A reason for this may be the definition of weathered stone is not exactly same between geological prospecting team and pre-drilling team, however it will not influence the result in this case. Those four data of pre-drilling around No. 20, shown in Fig. 2 are constantly away from the geological prospecting, which may address a systematic error or mistake while carrying out one of the survey, but even like this, they all follow the same trend.

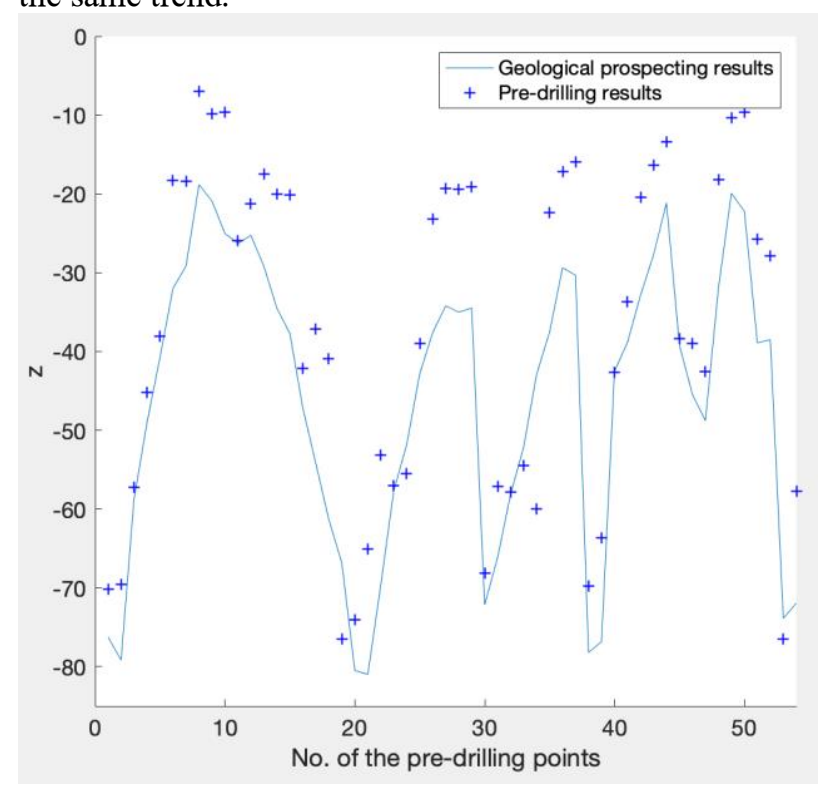

Fig. 2. Comparison of the results from the geological prospecting survey and the pre-drilling survey of the north building.

It can be seen that the trend of the two results is perfectly matched, however some of the data have a value of difference up to $15 \mathrm{~m}$. For instance, for those pre-drilling results around No. 10, (shown in Fig. 2) the adjacent result pair matches the geological reports, but those in between are not, which illustrates the fact that real geological strata are more complicated. Generally speaking, pre-drilling is more reliable and will be used as reference in construction of pile foundation. In this case, a further visual check with either bringing the depth results back to the 3-D map (Fig. 1) or to the site should be made.

\subsection{Estimation of the most optimal pre-drilling location}

There are 31 piles for the south building, therefore 31 optimal predrilling locations are estimated. The result of first 5 points is shown in Table 1, by a format of $\mathrm{x}$ and $\mathrm{y}$ coordinates. All of the results shown in Table 1 illustrate the trend that the $\mathrm{x}$ coordinates of them at the centres are constantly smaller than those for the optimal locations. In fact, Drill 1-5 along at the west edge of the building starting from the south west corner, which means they all have the similar slope direction (in this case, the surface of the strata decreases from south west to north east at these locations).

Table 1. Suggested optimal location for pre-drilling 1-5 with showing the coordinate and comparing to the pile centre.

\begin{tabular}{|c|c|c|c|c|c|}
\hline \multirow{2}{*}{$\begin{array}{c}\text { Drill } \\
\text { point }\end{array}$} & \multicolumn{2}{|c|}{$\begin{array}{c}\text { Coordinate for the } \\
\text { pile centre }\end{array}$} & \multirow{2}{*}{$\begin{array}{c}\text { Pile } \\
\text { diameter } \\
(\mathrm{mm})\end{array}$} & \multicolumn{2}{|c|}{$\begin{array}{c}\text { Coordinate for the } \\
\text { optimal pre-drilling } \\
\text { location }\end{array}$} \\
\cline { 6 - 6 } & $x$ & $y$ & & $x$ & $y$ \\
\hline $\begin{array}{c}\text { Drill } \\
1\end{array}$ & $\begin{array}{c}20432.8 \\
50\end{array}$ & $\begin{array}{c}100806 . \\
900\end{array}$ & 1600 & $\begin{array}{c}20433.5 \\
43\end{array}$ & $\begin{array}{c}100807 . \\
300\end{array}$ \\
\hline $\begin{array}{c}\text { Drill } \\
2\end{array}$ & $\begin{array}{c}20432.5 \\
50\end{array}$ & $\begin{array}{c}100814 \\
900\end{array}$ & 2000 & $\begin{array}{c}20433.4 \\
16\end{array}$ & $\begin{array}{c}100815 . \\
400\end{array}$ \\
\hline $\begin{array}{c}\text { Drill } \\
3\end{array}$ & $\begin{array}{c}20432.6 \\
00\end{array}$ & $\begin{array}{c}100821 . \\
900\end{array}$ & 2000 & $\begin{array}{c}20433.4 \\
66\end{array}$ & $\begin{array}{c}100822 . \\
400\end{array}$ \\
\hline $\begin{array}{c}\text { Drill } \\
4\end{array}$ & $\begin{array}{c}20432.5 \\
50\end{array}$ & $\begin{array}{c}100831 . \\
600\end{array}$ & 1800 & $\begin{array}{c}20432.5 \\
50\end{array}$ & $\begin{array}{c}100830 . \\
700\end{array}$ \\
\hline $\begin{array}{c}\text { Drill } \\
5\end{array}$ & 20423.8 & 100831. & 1800 & $\begin{array}{c}20424.5 \\
79\end{array}$ & $\begin{array}{c}100831 . \\
150\end{array}$ \\
\hline
\end{tabular}

As it is described in section 2, 13 points are analysed for a single pile, and those 13 estimated height of strata $\left(z_{p}\right)$ for Drill 1-5 are shown in Table 2. It can be seen that the biggest difference between $z_{p}$ for one pile is larger than the pile diameter, in other words, the slope of the strata at a certain angle is sharper than 45-degree. The biggest difference among these five occurs at Drill 2, which is $2.32 \mathrm{~m}$, equivalent to 1.16 times of the pile diameter of Drill 2.

Table 2. Estimations of $z p, i$ for Drill 1-5 in (m). $z p, 13$ indicates z at the centre.

\begin{tabular}{|c|c|c|c|c|c|}
\hline & Drill 1 & Drill 2 & Drill 3 & Drill 4 & Drill 5 \\
\hline$z_{p, 1}$ & -54.10 & -58.06 & -60.17 & -57.37 & -52.35 \\
\hline$z_{p, 2}$ & -54.44 & -58.57 & -60.61 & -57.50 & -52.83 \\
\hline$z_{p, 3}$ & -54.48 & -58.88 & -60.82 & -57.78 & -53.16 \\
\hline$z_{p, 4}$ & -54.44 & -58.60 & -60.80 & -58.12 & -53.54 \\
\hline$z_{p, 5}$ & -54.05 & -58.31 & -60.51 & -58.43 & -53.63 \\
\hline$z_{p, 6}$ & -53.71 & -57.72 & -60.08 & -58.66 & -53.67 \\
\hline$z_{p, 7}$ & -53.23 & -57.10 & -59.55 & -58.70 & -53.28 \\
\hline$z_{p, 8}$ & -52.94 & -56.56 & -59.29 & -58.55 & -52.95 \\
\hline$z_{p, 9}$ & -52.69 & -56.56 & -59.09 & -58.11 & -52.47 \\
\hline$z_{p, 10}$ & -52.69 & -56.66 & -59.07 & -57.67 & -52.24 \\
\hline$z_{p, 11}$ & -53.13 & -57.14 & -59.40 & -57.40 & -52.01 \\
\hline$z_{p, i 12}$ & -53.66 & -57.53 & -59.83 & -57.28 & -52.11 \\
\hline$z_{p, 13}$ & -53.66 & -57.63 & -59.86 & -58.06 & -52.82 \\
\hline
\end{tabular}

Even the depth difference can be calculated as it is described above, the actual strata is distributed in 3-D, which means it is hard to give out and "angle" of the 
strata from any 2D plots. However, after meshing $\mathrm{x}, \mathrm{y}$ and $\mathrm{z}$, any required angle of strata at any location can be estimated using the method described in this work. For instance, $z_{p, 3}$ for Drill 2 and $z_{p, 9}$ for it are exactly at a diagonal (positioned 180 degrees opposite), so it is better to say "at the direction along this diagonal", the angle of the strata equals to their difference over the pile diameter.

\subsection{Further Analysis}

In order to get more accurate estimations of optimal predrilling locations, a secondary analysis can still be made. In practice, more than one pre-drilling are often carried out for each pile foundation in complex scenarios, especially for those with large pile diameters (normally bigger than $2 \mathrm{~m}$ ). To do that, re-building the model described in 2.2 with inserting the newly gained predrilling data at the initial optimal location and hence the new optimal(deepest) location and the respective depth could be found. If their depth difference between all points is smaller than a safety factor, then there will be no need to do the second pre-drilling, vice versa. Unfortunately, this method can hardly be used for those drilling points located at boundary effected regions, because this method is not suitable at boundary conditions. Additional survey data outside the boundary area will be needed if wish to perform such analysis.

\subsection{Benefits in Settlement}

The costs of pile foundation construction through different layers (soil, strong weathered rock, medium weathered rock, Aeolian rock) are extremely different. The cost of pile foundations in weathered rock can be 5 times higher than in soil. In addition, such classification of layer is often difficult to be recognised and record insitu using traditional method, e.g. examine the specimen brought up by pile drivers. Moreover, the cost of piles embedded through partly rock is more complicated to confirm, and this always cause varies disputes in settlements after the construction. The model introduced in this work can be another helpful way to confirm the rock embedded length, and even the different types of rock distributed in the pile by using known data (geological prospecting survey and pre-drilling survey), which is more convinced as they are given by a third party.

Based on the description in 3.2 and 3.3, the crosssectional surface area of a pile is illustrated by a number of points (13 points in this work), so both full or partly rock can be represented. Thus, the level and the volume of rock in the pile can be served as an additional evidence for later settlement along with other traditional recognised evidences. Furthermore, if there is a need to analyse different types of rock's distribution, the "surface of strata" can also be substituted by the "surface of specific strata" and the same technique could also be used.

\section{Conclusion}

In conclusion, this paper develops a numerical model using existing geological prospecting data to determine optimal pre-drill location. A secondary analysis can be made to get the optimal location of the second predrilling for large diameter piles or more complex scenarios. Comparing to traditionally method of either choosing the pile centre or uniformly choosing a few pre-drilling points within one pile, the sorting process of optimal location suggested by this work is much more accurate and efficient. It can also minimise the number of pre-drillings needed to further reduce the cost without sacrifices. In addition, the model is also helpful to provide new forms of evidence for pile construction settlements.

\section{Acknowledgement}

The data from this work was supported by Wanlijia (Shenzhen) Ltd. This work was partly funded by Shenzhen Boyuda Building Technology Ltd.

\section{References}

1. D. V. Karandikar, Indian Geotechnical J., 48, (2018)

2. F. G. Bell, Foundation Engineering in Difficult Ground, (2013)

3. Code for Design of Building Foundation (GB500072011) 60,8.5.6 6, (2011)

4. Engineering geology handbook ( $4^{\text {th }}$ edition), 525528, (2007)

5. Standard for geotechnical investigation of tall buildings (JGJ/T 72-2017) 4.3.3, 4 (2017)

6. Y.Wang, Determination of bearing layer of cast-inplace pile foundation in high-rise buildings under complex geological conditions, (2003)

7. C. Luo, Construction of Punch Filling-pile in the Terminal of Guangzhou New Baiyun Intertional Airport under Karstic Geological Condition, T.S.T, 4th issue, (2002)

8. Z. Zhao, W. Wang and J. Yan, Sensitivity alaysis of mechanical parameters of different rock layers to the stability of coal roadway in soft rock strata, the S.W. J.,2013, (2013) 